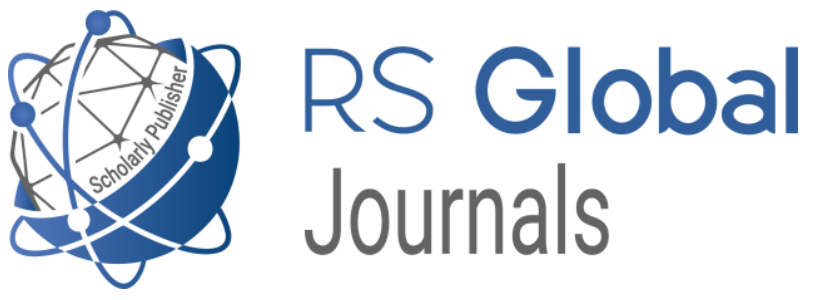

Scholarly Publisher

RS Global Sp. z O.O.

ISNI: 0000000484952390

Dolna 17, Warsaw, Poland 00-773

Tel: +48226022703

Email: editorial_office@rsglobal.pl

JOURNAL International Journal of Innovative Technologies in Social Science

p-ISSN

2544-9338

e-ISSN

2544-9435

PUBLISHER

RS Global Sp. z O.O., Poland

ARTICLE TITLE IMPLEMENT SCHOOL READINESS PROGRAM ON THE

PILOTING SUPPORTIVE WAYS TO EFFECTIVELY EXAMPLE OF TBILISI KINDERGARTENS

$\operatorname{AUTHOR}(\mathbf{S})$

Nino Labartkava, Tamar Saginadze

Nino Labartkava, Tamar Saginadze. (2021) Piloting Supportive Ways to Effectively Implement School Readiness Program on the

ARTICLE INFO Example of Tbilisi Kindergartens. International Journal of Innovative Technologies in Social Science. 2(30). doi: 10.31435/rsglobal_ijitss/30062021/7557

DOI https://doi.org/10.31435/rsglobal_ijitss/30062021/7557

RECEIVED

17 April 2021

ACCEPTED

26 May 2021

PUBLISHED

31 May 2021

LICENSE

This work is licensed under a Creative Commons Attribution

4.0 International License.

(C) The author(s) 2021. This publication is an open access article. 


\title{
PILOTING SUPPORTIVE WAYS TO EFFECTIVELY IMPLEMENT SCHOOL READINESS PROGRAM ON THE EXAMPLE OF TBILISI KINDERGARTENS
}

\author{
Nino Labartkava, PhD in psychology. Associate Professor Faculty of Psychology and Educational \\ Sciences Tbilisi State University, Georgia. Early childhood education program manager at National \\ center for teachers professional development
}

Tamar Saginadze, Early childhood education program consultant at National center for teachers professional development

DOI: https://doi.org/10.31435/rsglobal_ijitss/30062021/7557

\section{ARTICLE INFO}

Received 17 April 2021

Accepted 26 May 2021

Published 31 May 2021

\section{KEYWORDS}

school readiness program, School Readiness Educational Standard, kindergarten, Observation.

\begin{abstract}
In 2015, a school readiness program was created for children who will turn 5 before the start of the school year and will start studying at the first grade of school in September. The components of the school readiness program are: «School Readiness Educational Standard», a teacher's guideline, a collection of activities describing specific activities and provided relevant supplements. The goals of the study are: Study of the course of school readiness program on the example of Tbilisi kindergartens; Based on the situation, developing methodology for effective implementation of school readiness program.

The project was implemented in Tbilisi. The selection of experimental and controlled preschool institutions was based on the existence of similar infrastructure (newly built building, existence of a yard) and three or four large size school readiness groups in kindergarten.

As a result of the works carried out, experimental preschool institutions have improved in the following directions: Educators conduct dialogue and ask children questions individually and in small groups; Children have the opportunity to engage in different types of activities and games (games with rules, role playing games, movable games, creative activities); Children can independently take and use learning and gaming resources; The group uses handmade and secondary resources; Group space is organized into thematic centers; The natural materials are used in the group; Children can independently take toys and resources; Educators have planned and prepared a wide variety of activities (activity, games with rules, role playing games, project) related to the topic; Educator observes children in order to evaluate them.
\end{abstract}

Citation: Nino Labartkava, Tamar Saginadze. (2021) Piloting Supportive Ways to Effectively Implement School Readiness Program on the Example of Tbilisi Kindergartens. International Journal of Innovative Technologies in Social Science. 2(30). doi: 10.31435/rsglobal_ijitss/30062021/7557

Copyright: (C) 2021 Nino Labartkava, Tamar Saginadze. This is an open-access article distributed under the terms of the Creative Commons Attribution License (CC BY). The use, distribution or reproduction in other forums is permitted, provided the original author(s) or licensor are credited and that the original publication in this journal is cited, in accordance with accepted academic practice. No use, distribution or reproduction is permitted which does not comply with these terms.

1. Introduction. In 2015, a school readiness program was created for children who will turn 5 before the start of the school year and will start studying at the first grade of school in September. The components of the school readiness program are: "School Readiness Educational Standard" (this document describes what skills a child should have entering school and provides information about what skills should be developed at an early age), a teacher's guideline (methodological guide), a collection of activities describing specific activities and provided relevant supplements.

The school readiness program is a curriculum with its contents and structure, or a frame document that gives us the direction of goals, content and methodology. 
The school readiness program has 4 basic grounds, which are in all processes within the framework of the program. In particular,

1. The process is going on in the form of a game

- During the course of the program, different types of games should be encouraged;

- The use of the game should be - during different activities and processes;

- The environment must support a wide variety of games.

2. Group unity relationships;

- The educator in the group should support the formation and cooperation of positive

- Children in the group should be appreciated, encouraged, given the opportunity to choose; their opinions considered;

- Feedback should contribute to the formation of a "Positive I" concept;

- Expression of empathy should be encouraged;

- Settlement of conflicts should be made in a peaceful way;

- The group's positive management strategies should be used.

3. High thinking skills

- Educators should be able to raise open questions;

- It should be encouraged to search for ways to solve the problem.

4. Compliance - Inclusion

- The environment must comply with the principles of universal design;

- All children must be involved in the process;

- Resources should be available to children;

- The interests of children should be studied, taken into consideration;

- There must be a team of inclusive education specialists.

The school readiness program also provides for the principles of arrangement of the physical environment of the school and the resources that are recommended for the multi-faceted and full development of a child in the school readiness group.

Physical environment

- Space must be organized into spaces (circle meetings, cubes, literacy, fine and applied arts, role-playing games, science and quiet space)

- In the group there must be visual designations - e.g., visualized day mode; indications for spaces and resources.

- Group resources should be relevant to the program. Secondary and natural materials should also be allocated. Materials should be sorted into categories.

\section{Schedule}

The schedule of the day should include the main activities of the program, such as the first and summary meeting in the circle, research and discovery, movable games, activities in small groups, book time, performing art.

The program also provides recommendations on child nutrition and transition periods.

Observation of a child and recording of children.

The program provides recommendations on ways to document the activities and development

Based on the relevance of the issue, the National Center for Professional Development of Teachers planned to evaluate the course of the school readiness program, reveal challenges and strong sides, develop and implement an intervention program based on the needs revealed.

\section{Goals and objectives}

The goals and objectives of the study were determined by the relevance of the issue:

\section{Goals:}

1. Study of the course of school readiness program on the example of Tbilisi kindergartens;

2. Based on the situation, developing methodology for effective implementation of school readiness program T.A.M.A.SH.I.;

3. To develop recommendations for the program's efficient implementation and improvement.

We defined the tasks of the research:

1. Selection of experimental and control kindergartens;

2. Assessment of the basic situation of school readiness program; 
3. Considering the results obtained, the development of the intervention plan (training, practical supervision and schedule);

4. Implementation of intervention;

5. Assessment of the outcome of the intervention;

\section{Method}

\section{Selection}

The project was implemented in Tbilisi. The selection of experimental and controlled preschool institutions was based on the existence of similar infrastructure (newly built building, existence of a yard) and three or four large size school readiness groups in kindergarten. See Table 1.

Table 1.

\begin{tabular}{|c|c|c|c|c|c|c|c|c|c|c|c|}
\hline $\mathbf{N}$ & 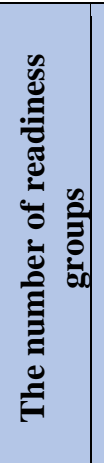 & 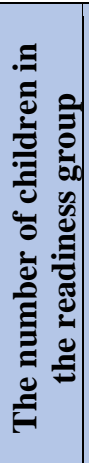 & 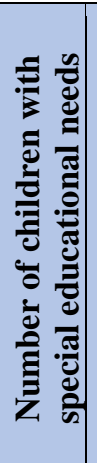 & 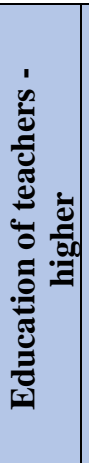 & 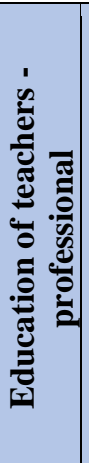 & 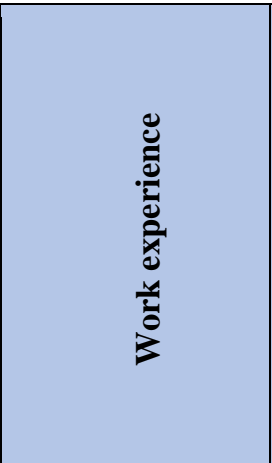 & 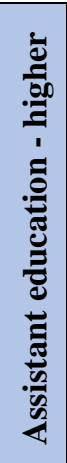 & 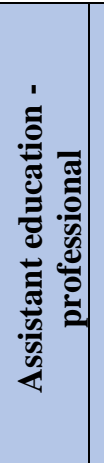 & 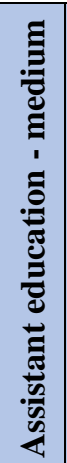 & 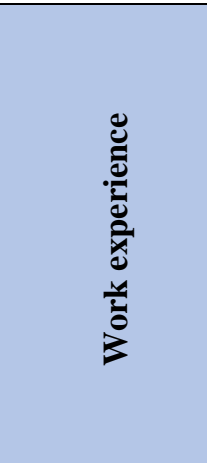 & 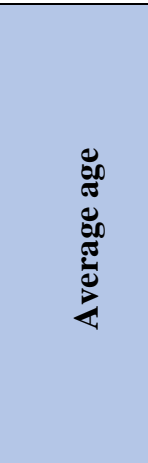 \\
\hline 1 & 3 & 166 & 7 & 5 & 1 & \begin{tabular}{|c|} 
Average -7 years \\
Minimum - 1 \\
maximum - 26 years.
\end{tabular} & 4 & 3 & & 3 year & $\begin{array}{c}41 \\
(\operatorname{Min}-33, \\
\text { Max -56) }\end{array}$ \\
\hline 2 & 4 & 128 & 0 & 7 & 0 & $\begin{array}{l}\text { Average - } 2 ; \\
\text { Min (1 months); } \\
\text { Max (6 years) }\end{array}$ & 1 & 3 & 1 & $\begin{array}{l}\text { Average - 2; } \\
\text { Min (1 month); } \\
\text { Max (6) }\end{array}$ & $\begin{array}{c}43 \\
\text { (Min 26, } \\
\text { Max 59) }\end{array}$ \\
\hline 3 & 3 & 120 & 3 & 6 & & $\begin{array}{c}1 \text { year } \\
\text { (Min }-1 \text { month } \\
\text { Maximum }-2 \text { years) }\end{array}$ & 1 & 4 & 1 & 1 year & $\begin{array}{c}37 \\
\text { (Min -28; } \\
\text { Max 59). }\end{array}$ \\
\hline
\end{tabular}

\section{Method of research.}

The basic situation was evaluated by observing focus group and the process of educational program.

Focus Group results.

As a result of the focus groups of educational personnel and administration of all three preschool institutions, it was revealed that:

- From the school readiness program components, respondents are mainly familiar with and use a collection of program activities, where individual activities are described and presented with appropriate attachments;

- Selection of activity or topic from the collection of activities is taken into consideration depending on the season, holiday or existing resources, and not by the interests of children;

- Respondents are less aware of the basis of the program (see higher) in the process of work;

- "Transition periods", distribution of children in small groups and working as small groups, management of the group, working with children with special educational needs, observation of children and systematic production of records were considered a challenge.

Based on the results obtained, we have carried out School Readiness Program Training. The training included issues such as:

- School readiness program and its constituent components (standard, methodological guide, collection of activities and opportunities for use);

- Main grounds of school readiness program - role of the game in child learning and development, game types, formation of group unity, strategies for promoting high thinking skills, individual approach;

- School readiness group schedule and daily activities; 
- Child-oriented educational process planning - specifics of creating topics and week plans,

- Observation of a child and recording;

- To facilitate the transition process of a child in school.

40 employees of all three preschool institutions were trained with this training module.

\section{Observation of the educational process}

After the training, the course of the school readiness program was observed and assessed.

The instrument provided the opportunity to evaluate the course of the program according to the following categories:

1. Main basics of the program;

2. Physical environment and resources of the group;

3. Daily activities and processes;

4. Promotion of child learning and development (development fields, thematic directions);

5. Planning and evaluation.

Each field was broken up into more accurate situations / behaviours. Each situation / behaviour was given a rating according to the frequency of detection. Never 1, sometimes - 2; often 3. It was not estimated - 0 .

Observation was made by 2 experts. The basic situation was studied at the beginning of the semester and the outcome of the intervention was at the end of the semester.

The relative analysis of the observations carried out at the beginning of the educational semester and at the end of the semester is shown below.

\section{Staff consultations}

Based on the needs, the schedule and topics of consultations were developed.

\section{Consultations were conducted on topics:}

- Divide the group into spaces, arrange the physical environment;

- Strategies to encourage the game; use the game during transitions;

- Open questions;

- Observation of a child and recording;

- Effective feedback;

- Portfolio production.

- Develop topics considering available resources;

- Natural and secondary resources and their types;

- Day schedule;

- Management of conflicts and emotions - Lighthouse, Turtle Technique;

- Specific strategies to engage a child with special educational needs in the activities according to a child's interests and to encourage work in centers, services in the city for children with special educational needs.

- Recommendations regarding the management of child behaviour.

The following methods were used during the consultation: demonstration, video analysis, shooting of the working process and then its introspection, the use of self-esteem forms to evaluate the educational process and the physical environment.

\section{Results intervention \\ Comparative analysis of the observational results of the baseline situation and \\ 2.1. The main basics of the program \\ The educator / assistant presents dialogue and questions children individually and in small groups.}

At the beginning of the semester, in the 1st Experimental Preschool, sometimes three groups had a situation when the teacher conducted a dialogue and asked children questions, and in one group the similar situation was not revealed at all. At the end of the semester, it was often revealed in three groups, and sometimes in one group.

At the beginning of the semester, in the 2nd Experimental Preschool, the teacher's work with small groups was not revealed in two groups, and sometimes it was revealed in one group. At the end of the semester, the situation in all three groups was sometimes revealed.

At the beginning of the semester, in the controlled school (3), the caregiver in the two groups of the kindergarten sometimes asked questions to children individually and in small groups, and in one 
group there was no such thing revealed. At the end of the semester, this situation was not revealed in any of the groups.

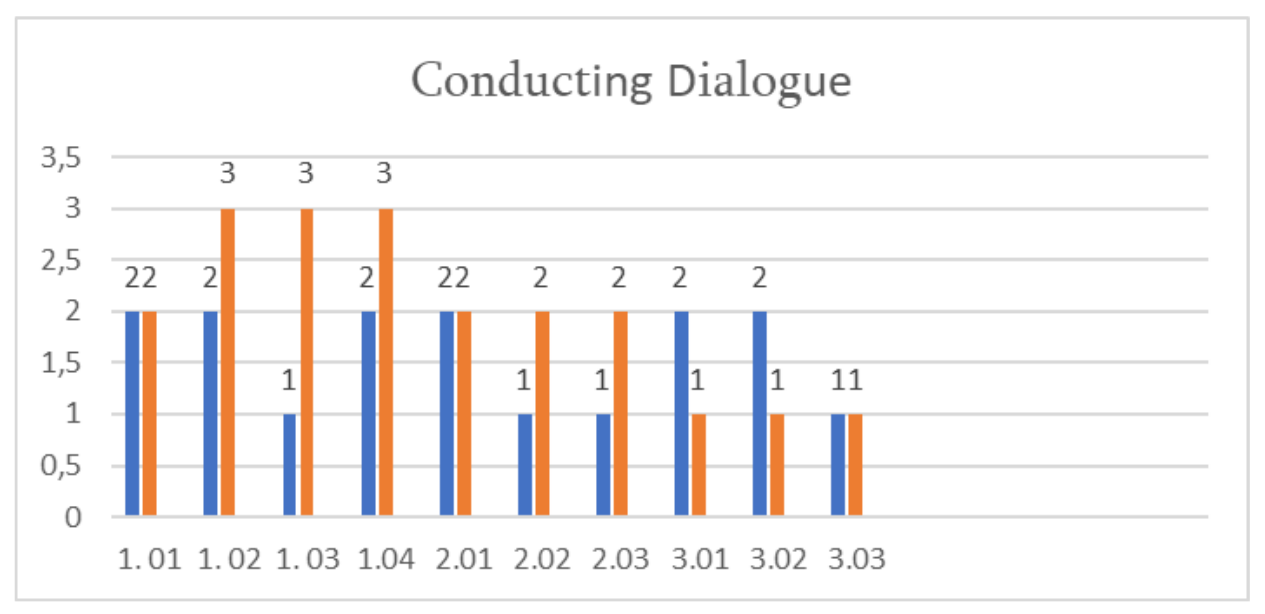

\section{Diagram 1.}

It is assumed that after the consultation, the educators began to ask questions more to conduct dialogue, because this situation is often found in 3 groups of 1st Experimental Kindergarten, sometimes in the two groups of Second Experimental Kindergarten.

In the two groups of the controlled kindergarten, this situation took place immediately after training, and at the end of the semester the picture is deteriorating. The reason for this can be losing post training motivation due to the absence of proper support.

Children have the opportunity to engage in different types of activities and games (games with rules, role playing games, movable games, creative activities, etc.)

In October, the situation in three groups of 1st Experimental Preschool (1) was not revealed, and was revealed sometimes in one group. At the end of the semester, different types of games sometimes had a place in two groups, the situation in one group was still not revealed, and in the group, where the situation sometimes had a place, had not changed.

In the study of the basic situation in the 2nd Experimental Preschool (2), the situation sometimes was revealed in one group, the circumstances were maintained in this group at the end of the semester, in the study of the basic situation, the situation in 2 groups was not revealed, but at the end of the semester, it sometimes took place in the same groups.

At the beginning of the semester, in the controlled school (3), children in the two groups sometimes had the opportunity to engage in different types of activities or games, and this was not identified in one group. At the end of the semester, the circumstances did not change.

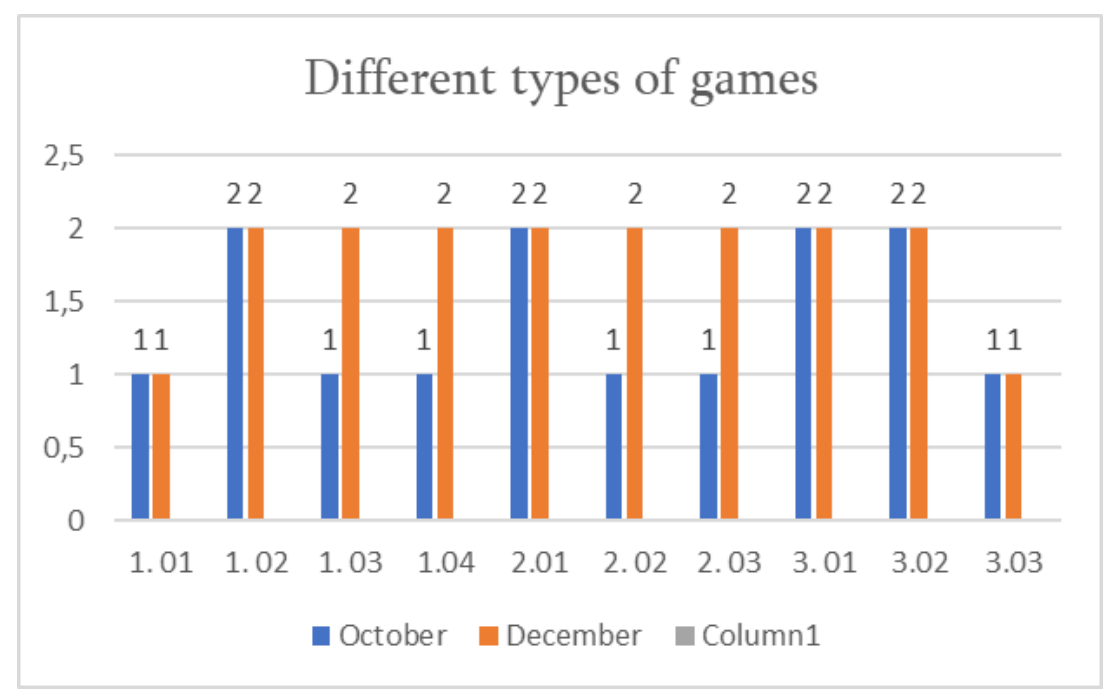

Diagram 2. 
As it appears on the diagram 2. After consultations, the circumstances were changed in each two groups of both experimental kindergartens.

In the controlled kindergarten, the circumstances are unchanged, but it is necessary to note that at the beginning of the semester in the two kindergartens, children had the opportunity to engage in diverse games.

Activities are mainly in the form of a game.

While studying the basic situation, the educational process was sometimes carried out in the form of a game in all four school readiness groups of 1st Experimental Preschool. At the end of the semester, the process is often in the form of a game in two groups of the kindergarten. In the other two groups the circumstances have not changed.

2nd Experimental Preschool. At the beginning of the semester, the situation in all three groups was sometimes revealed, and the circumstances had not changed at the end of the semester.

At the beginning of the semester, in the controlled kindergarten, the activities of the two groups were often in the form of the game, and sometimes in one. And at the end of the semester, the circumstances were maintained with two groups. With the first group, the situation is still often seen, and with the third group still sometimes.

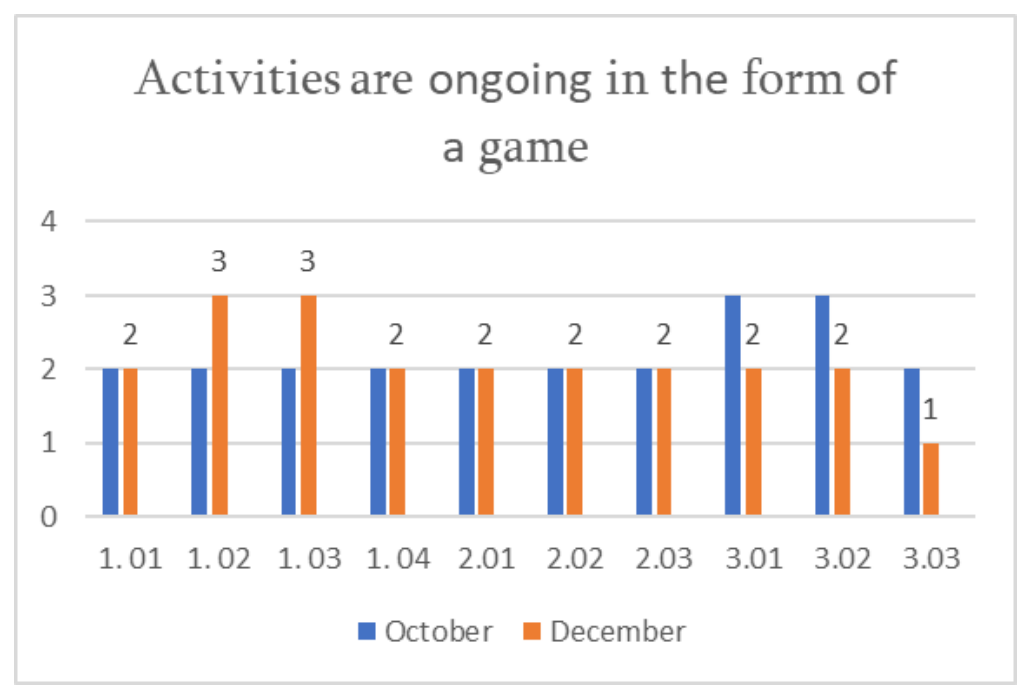

\section{Diagram 3.}

Apparently, the situation has changed in the first Experimental Preschool institution. Which, we think, is the result of consultations. As for the controlled preschool institution, it is interesting that the circumstances in the two groups had not changed. It is noteworthy that the staff of this institution was distinguished with high motivation and was ready for changes after training. Which was revealed during the observation. But at the end of the semester, there was a change in staff. Also, no maintenance of the training effect had occurred.

During the routine activities and transitions during the day, the caregiver uses amusing elements of the game.

In the course of studying the basic situation, the process did not appear in all four groups of 1st Experimental Preschool institution (1). At the end of the semester, the picture had not changed in three groups, and in one group the caregiver sometimes uses the amusing game elements during routine activities and transactions.

At the beginning of the semester, two groups of 2nd Experimental Preschool did not have fun elements during transition. In one group, the caregivers sometimes used fun game elements. At the end of the semester, the picture was unchanged.

In the controlled preschool establishment (3), at the beginning of the semester, two kindergarten activities did not appear to have fun activities during routine activities, and in one group it often took place. At the end of the semester the picture was maintained with two groups, and in one group it was not revealed. 


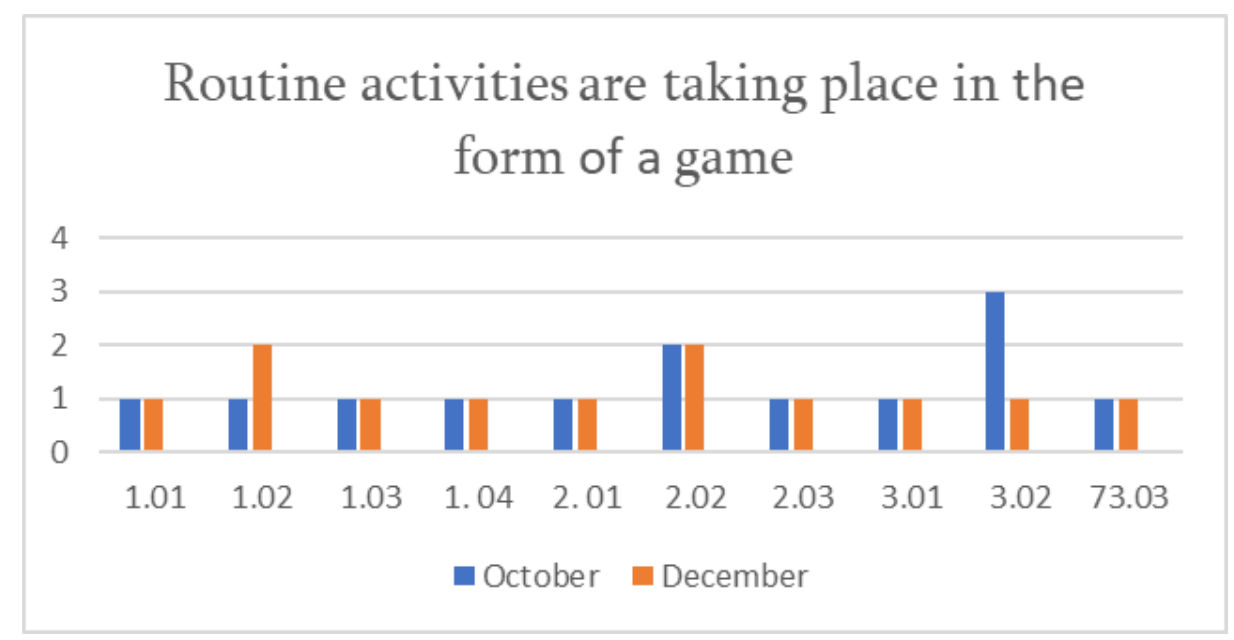

Diagram 4.

Apparently, introduction of game elements during routine activities requires continuation of the work in this direction. It is used in the 1st Experimental Preschool. It should be noted that routine activities were in the form of a game in one group of controlled kindergartens, but at the end of the semester the situation worsened, it is likely that this is caused by the change of staff.

\subsection{The group's physical environment and resources}

Children can independently take and use learning and gaming resources

In the beginning of the semester, in 1st Experimental preschool (1), the situation was not revealed in the two groups, and it was revealed sometimes in the two groups. At the end of the semester, it was often revealed in three groups and not in one group.

At the beginning of the semester, in the 2nd Experimental Preschool (2), children in all three groups were sometimes able to independently take and use the learning and gaming resources. At the end of the semester, it was often revealed in the two groups and sometimes in one group.

At the beginning of the semester, in the controlled preschool (3), the situation was sometimes revealed in the two groups of the kindergarten, it was not revealed in one group. At the end of the semester, it is often revealed in one group, the situation in the other two groups is unchanged.

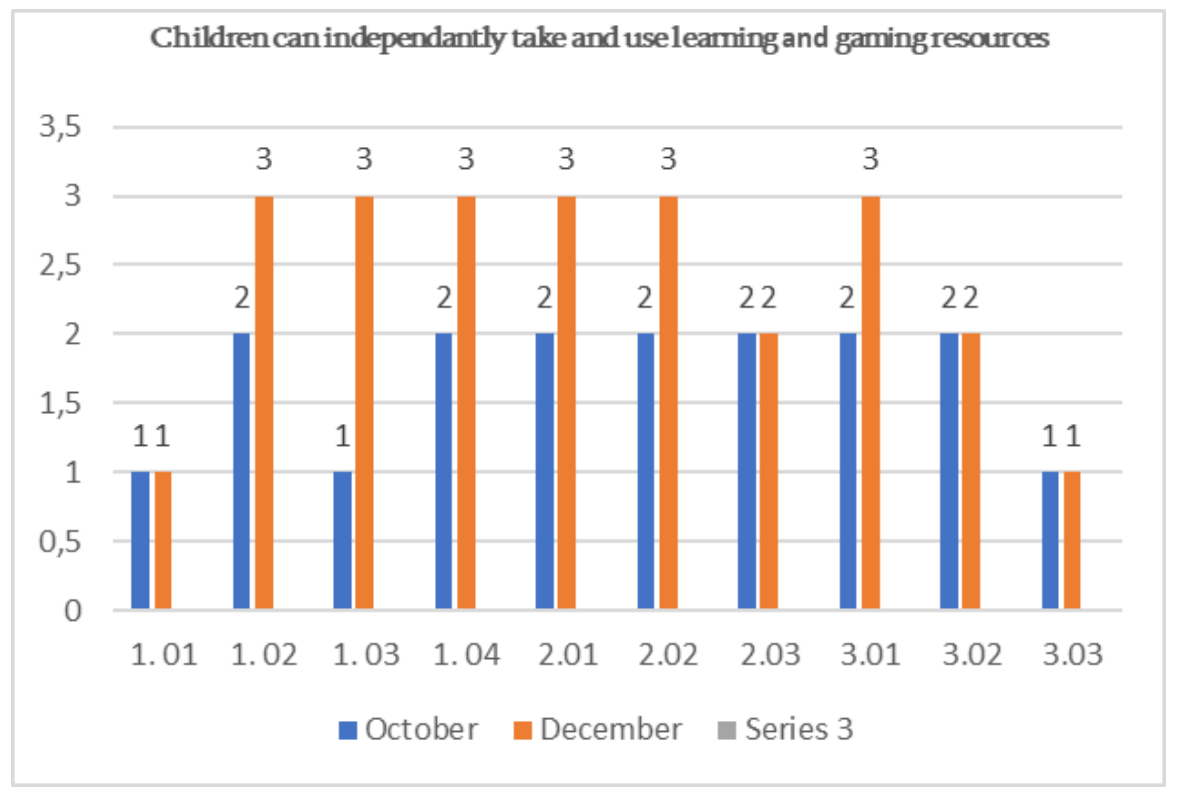

Diagram 5.

We think that after consultations, the educators have realized how important it is for the children to access their recourses, to achieve this, resources were arranged to be easily accessible to a child in 3 groups of the 1st Experimental Kindergarten, which is clearly visible from the diagram. Also, after the consultation in the group of the second kindergarten, the situation changed and the environment became tailored to a child, the resources could be used by the children themselves. 


\section{The group uses handmade and secondary resources}

At the beginning of the semester, in the 1st Experimental Preschool, there were no handmade and secondary resources in any group. At the end of the semester, there was no secondary and handmade resources in one group, and they were often used in two groups, sometimes in one group.

In the 2nd Experimental Preschool (2), none of the groups used secondary or handmade resources at the beginning of the semester, and at the end of the semester, they were sometimes used in two groups, often in one group.

At the beginning of the semester, (3) they were sometimes used in two groups of the controlled preschool, and not in one group. At the end of the semester the picture is unchanged.

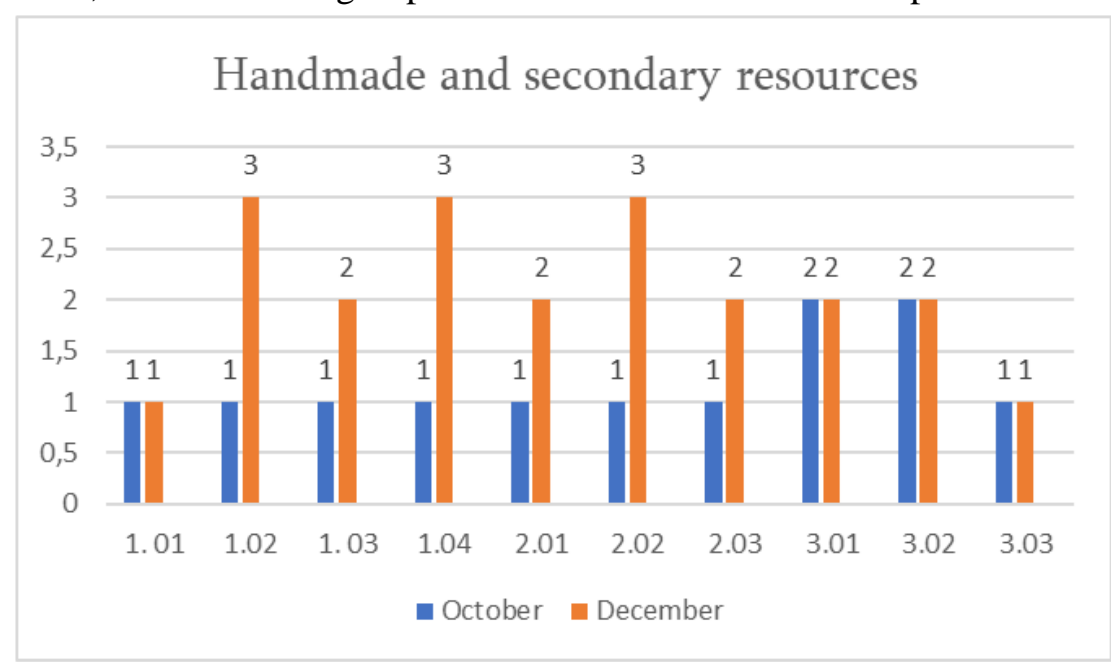

Diagram 6.

Creation of secondary and handmade resources seems to have been actively used in three groups of 1st Experimental Preschool, as well as in three groups of Second Experimental Kindergarten. The use of secondary and handmade resources has diversified and enriched the group's resources.

The group space is organized into at least 5 thematic centers

According to the school readiness program, it is desirable to be included in the group space: circle meetings, cubes, literacy, fine and applied arts, role playing games, and quiet spaces.

At the beginning of the semester, there was no space organized into thematic centers in any of the groups at the 1st Experimental Preschool (1). At the end of the semester, the centers were fully organized in three groups, partially in one group.

At the beginning of the semester, in 2nd Experimental Preschool (2), there was no space organized into centers in one group, it was partially organized in one group and fully in one group. At the end of the semester, the centers were fully organized in two groups, partially in one group.

After the training in the controlled preschool, the centers were fully arranged in two groups, and it is not arranged as centers in one group. The same picture was maintained at the end of the semester.

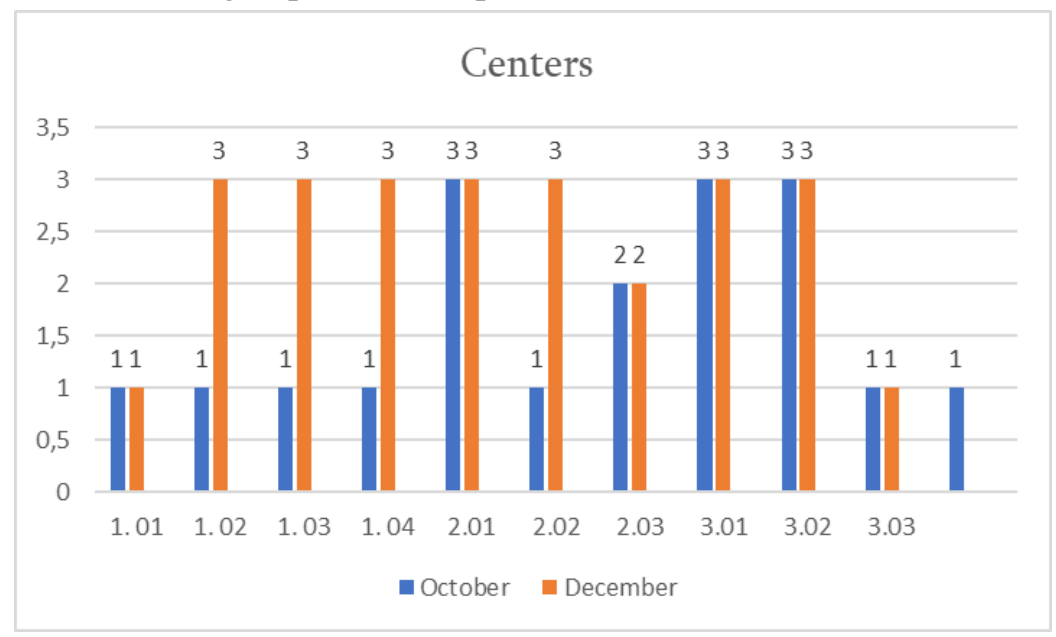

Diagram 7. 
It seems that after consultations, in the three groups of 1st Experimental Preschool and one group of Second Experimental institution, the groups were set up as centers. It was more convenient for children to work in different centers. After the training in the controlled preschool, the centers were arranged in two groups, and not in one group. The picture remained unchanged at the end of the semester.

The group has access to a wide variety of natural materials

At the beginning of the semester, there was no natural materials available in any of the groups of the 1st Experimental Preschool. At the end of the semester, sometimes three groups used natural materials, and one group did not.

At the beginning of the semester, in the 2nd Experimental Preschool, none of the groups used natural materials, and at the end of the semester, the situation improved, all three groups sometimes used natural resources.

At the beginning of the semester, in the controlled preschool, the two groups did not use natural materials, and one group sometimes used it. The picture did not change at the end of the semester.

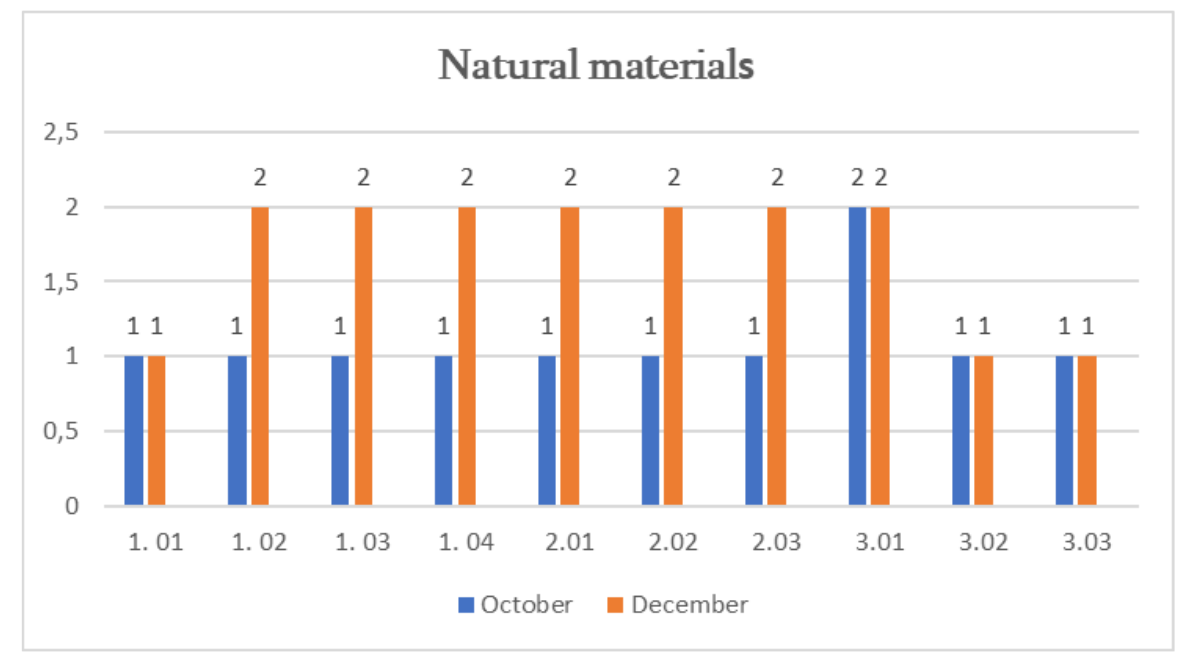

Diagram 8.

After the consultations, the picture changed in three groups of 1st Experimental Kindergarten, children were able to use natural materials. In the three groups of second preschool institution, the group was actively using natural materials as a resource. The picture in the controlled kindergarten remained unchanged.

\section{if needed}

The resource presented in the centers is sorted out so that children can easily find items

At the beginning of the semester, in the 1st Experimental Preschool, there were no resources sorted in any group. At the end of the semester, the resources in the three groups are partially sorted, in one group they are still not.

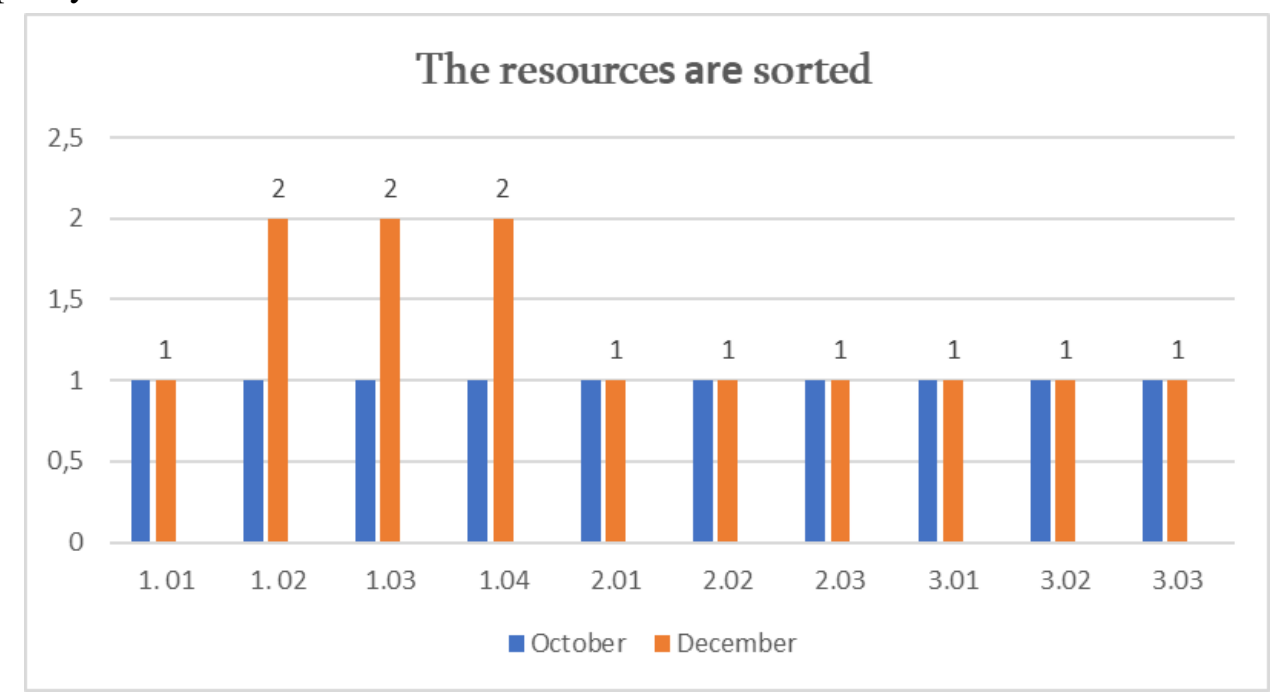

Diagram 9. 
At the beginning of the semester, in the 2nd Experimental Preschool, there were no resources in any of the groups sorted in a way that children could easily find items if needed. At the end of the semester, the picture had not changed.

At the end of October and at the end of the semester, this situation is not revealed in the controlled preschool institution.

The diagram states that the main picture is unchanged, in three groups of 1 st kindergarten, it is observed that only the educators arranged the resources so they are sorted in a way to be easily found by a child.

\subsection{Daily activities and processes}

The educator has well planned and prepared a wide variety of activities (activity, game with rules, role playing, project)

At the beginning of the semester, there were no well-planned activities by the carers observed in any of the groups of the 1st Experimental Preschool (1). At the end of the semester, there were a wide variety of activities planned in all four groups.

At the beginning of the semester, there was no variety of topic related activities by the caregiver observed in any of the groups of 2nd Experimental Preschool (2). At the end of the semester, all three groups had them sometimes.

In October, in the controlled preschool facility (3), the situation was sometimes shown in two groups, and the picture did not change at the end of the semester, and it was not revealed in one group in October, but was sometimes revealed at the end of the semester.

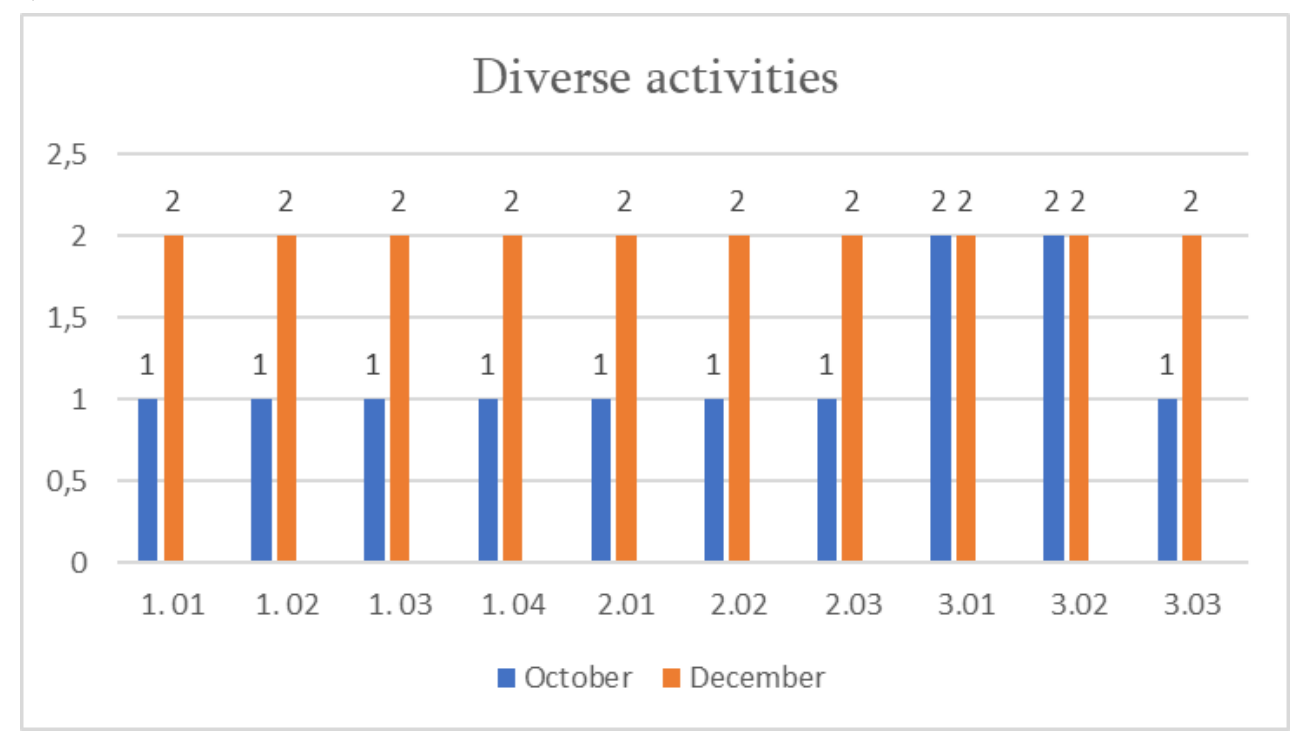

\section{Diagram 10.}

We assume that after the consultations, the educators realized how convenient and effective the planning of a variety of activities are, and apparently, all groups of both experimental kindergartens showed high results.

\subsection{Planning and evaluation}

The educator observes children with the aim of assessing them

At the beginning of the semester, in the 1st Experimental Preschool, there was no observation in any of the school readiness groups in order to evaluate children. At the end of the semester, this situation is sometimes revealed in all four groups.

At the beginning of the semester, in the 2nd Experimental Preschool, there was no observation in any of the groups in order to evaluate children. At the end of the semester, they were sometimes observing children in all three groups.

At the beginning of the semester, in the controlled preschool institution, no group was observed in order to evaluate children. The picture is unchanged at the end of the semester.

As shown on the diagram, after the consultations, the educators observed children in order to evaluate them in all groups of both preschool institutions. 


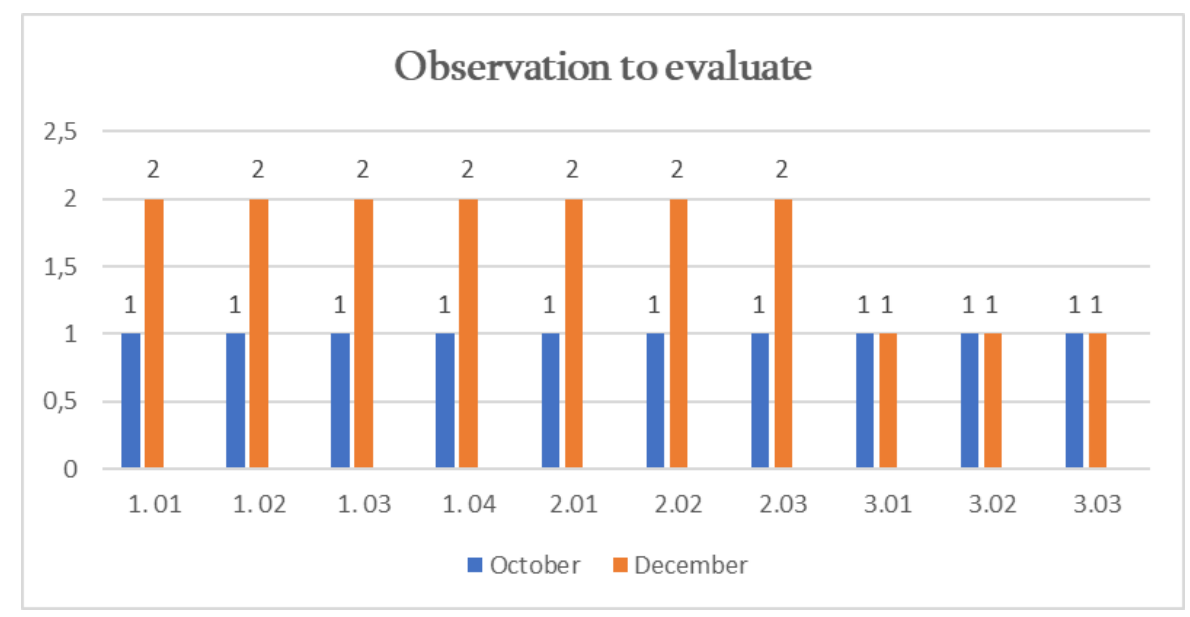

Diagram 11.

The educator fully fills out all components of the plan (e.g., activity, resource, individualization)

At the beginning of the semester, in the 1st Experimental Preschool (1), it was revealed that the educators in all four groups partially filled out all the components of the plan. At the end of the semester, it is completely filled out in two groups, and still partially in two groups.

At the beginning of the semester, in the 2nd Experimental Preschool, the caregiver sometimes filled out all the necessary components in two groups, and these graphs were not filled in one group. At the end of the semester, the caregiver of two groups fully filled out all the components of the plan, and partially in one group.

At the beginning of the semester, in the controlled preschool (3), the plan was partially filled out in two groups, and not in one group. At the end of the semester, there was also progress, namely, the plan is fully filled out in two groups, partially in one group.

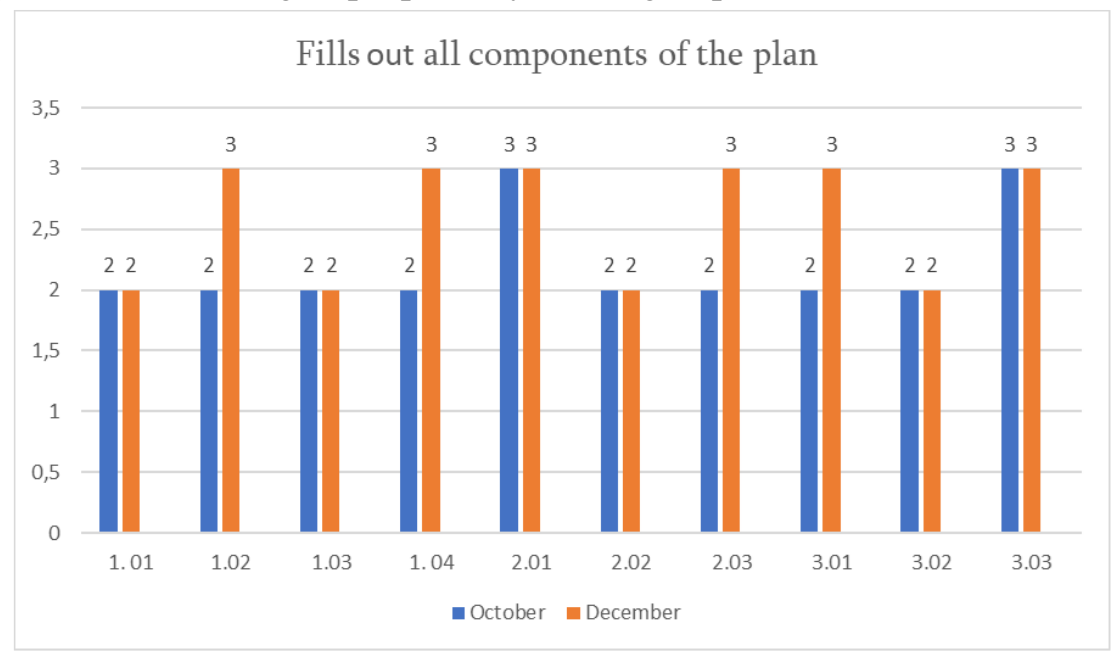

Diagram 12.

Educators try to take into consideration, complete all the components of the plan, but they are not able to manage this in some groups; they actively fill out all the components of the plan in two groups of 1st Experimental institution, and only in one group of 2nd Experimental institution. The caregiver of the controlled kindergarten fills out all components of the plan in one group.

5. Conclusions. As a result of the works carried out, experimental preschool institutions have improved in the following directions:

- Educators conduct dialogue and ask children questions individually and in small groups;

- Children have the opportunity to engage in different types of activities and games (games with rules, role playing games, movable games, creative activities);

- Children can independently take and use learning and gaming resources;

- The group uses handmade and secondary resources;

- Group space is organized into thematic centers;

- The natural materials are used in the group; 
- Children can independently take toys and resources;

- Educators have planned and prepared a wide variety of activities (activity, games with rules, role playing games, project) related to the topic;

- Educator observes children in order to evaluate them.

Only one preschool institution has been improved in the following directions: activities, routine activities are mainly in the form of a game, resources are sorted by category.

Therefore, in the direction of planning and implementation of transition periods and routine activities, the work is still necessary to be continued.

It should be noted that the above mentioned situations often remained unchanged in the controlled kindergarten, or in some cases worsened. In particular, the circumstances were worsened in the following directions: a caregiver conducts the dialogue, asks the children questions, the activities, the transition periods are mainly in the form of a game. The reason for this may be the fact that the enthusiasm that emerged after training was gradually reduced because of the lack of support or that the personnel changed during the educational period.

It is also noteworthy that in one group of each controlled preschool institution, the improvement is shown in the following directions: children can independently take and use gaming resources, the educator fills out all components of the plan.

\section{Recommendations.}

- In addition to training in new preschool institutions, it is important to carry out consultations / coaching on the ground - to strengthen the sustainability and habits of the knowledge obtained;

- Intervention and changes also affected the development of a wide variety of types of games, organizing the physical environment, implementing the schedule of the program, initiating the process of observing a child and documenting the results, the next stage of intervention is desirable to provide two other basic foundations of the program - formation of group unity (social and emotional spheres) and support of the development of high intellectual skills;

- After the end of the intervention, detailed recommendations for the municipalities of Georgia should be prepared in the form of a publication for the effective implementation of the school readiness program.

Acknowledgments. I want to express my sincere gratitude Berika Shukakidze Director of National center for teachers professional development for the inspiration to study the situation as the school readiness program works, As well as Anna Janelidze, Tamta Kukhaleishvili, Nino Jijavadze, Tamar Bakradze and Nino Guliashvili to support the study process.

\section{REFERENCES}

1. Pirls2011. Literacy report. National Center for Assessment and examinations.

2. Britto, P.R. \& Limlingan, M.C. (2012). School readiness and transitions: A companion to a child friendly schools Manual. New York: UNICEF.

3. Maxwell, K.L. \& Clifford, R.M. (2004). School readiness assessment. Young children (Research in Review). National Association for the Education of Young children; Bruner, C. \& Copeman, A. (2003). Measuring children's school readiness: Options for devoicing state baselines and benchmarks. State early childhood policy Technical assistance Network. Retrieved from http://www.finebynine.org/uploaded/file/Baselines.pdf.

4. School Readiness Educational State Standard. Retrieved from https://matsne.gov.ge/ka/document/view/2958964?publication=0

5. School Readiness Program Play for learning and development. The Educator's Guide. Ministry of Education and Science of Georgia, UNICEF, 2015.

6. Preschool education quality research in Georgia. Short Review - 2018. 